\title{
КОЛИЧЕСТВЕННОЕ ИССЛЕДОВАНИЕ ДВУХ РАННЕЛЛАНДОВЕРИЙСКИХ БИОГЕРМОВ НА О-ВЕ ХИИУМАА (ЭСТОНСКАЯ ССР)
}

Слабая обнаженность биогермных комплексов Эстонии затрудняет их палеоэкологическое исследование. Это в полной мере относится и к биогермам юуруского горизонта раннего лландовери, распространяющимся в Северо-Западной Эстонии. Поскольку лландоверийские, и особенно раннелландоверийские, биогермы в мире очень мало известны, то с точки зрения экогенеза рифостроящих организмов состав и количественные взаимоотношения каркасных организмов в биогермах этого возраста представляют несомненный интерес.

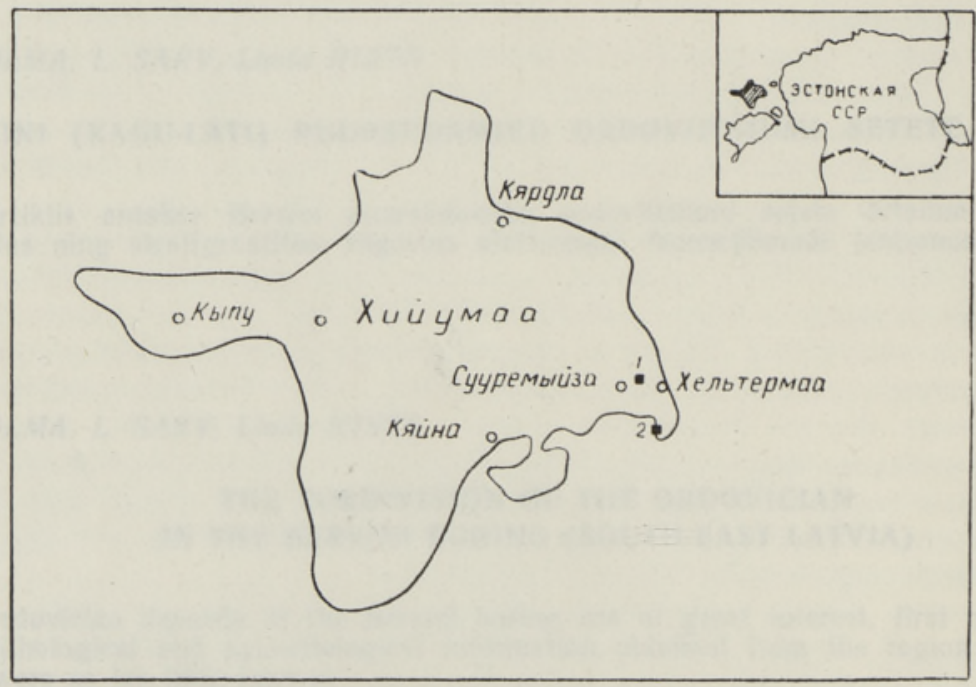

Рис. 1. Местонахождения изученных биогермов на о-ве Хийумаа: 1 - Хиллисте, 2 - Сарве.

Авторами исследовались два небольших биогерма хиллистеской пачки юуруского горизонта на о-ве Хийумаа, один - в каменоломне Хиллисте, другой - на западном побережье п-ва Сарве (рис. 1). В Хиллисте изучался вертикальный разрез через биогерм высотой около $2 \mu$ и длиной $7,5 \mu$ (рис. 2), в Сарве - часть кровли биогерма, действительные 


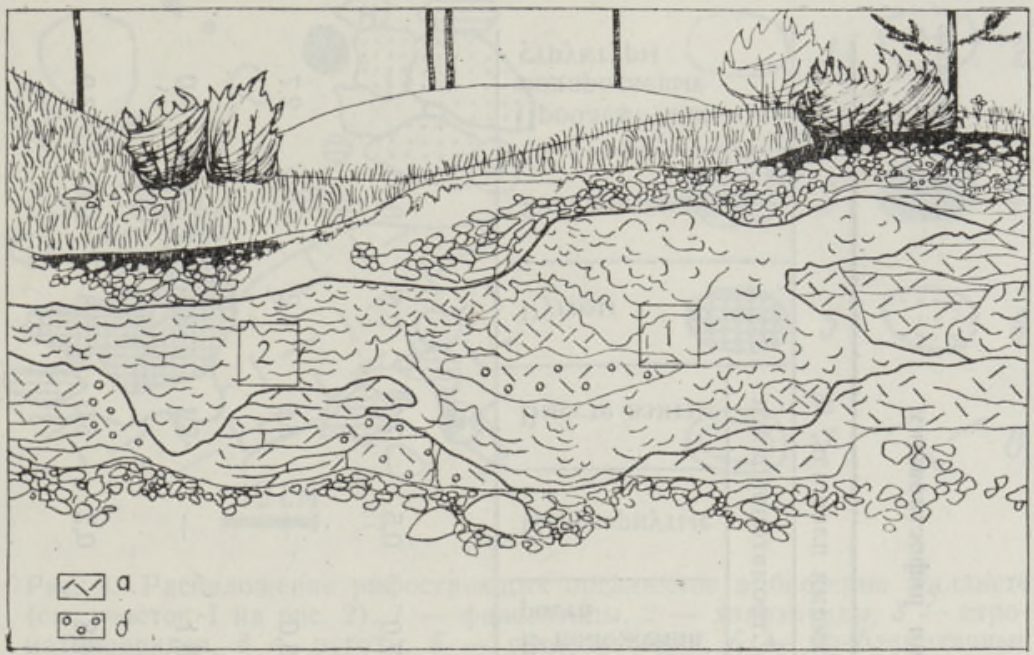

$1 M$

Рис. 2. Полевой рисунок биогерма в каменоломне Хиллисте. Пронумерованные квадраты обозначают участки подсчета количественных соотно шений каркасных организмов. $a$ - детритовая порода, $\sigma$ - грубообломочная порода.

размеры и форма которого остались невыясненными. Понятно, что такой более чем скромный материал недостаточен для далекоидущих выводов относительно количественных характеристик хиллистеских биогермов в целом, но он позволяет составить определенную картину о количественных взаимоотношениях основных групп рифостроящих организмов в одном типе биогермов.

У обоих биогермов было зарисовано на миллиметровую бумагу по два участка, при определении площади которых исходили из технических возможностей и размеров колоний рифостроящих организмов. На рисунки * наносились контуры остатков рифостроящих организмов, после чего подсчитывалась (в процентах) занимаемая ими площадь по следующим категориям: 1) фавозитиды в положении роста, 2) фавозитиды с перевернутыми колониями, 3) хализитиды, 4) все табуляты в целом, 5) строматопороидеи в положении роста, 6) строматопороидеи с перевернутыми колониями, 7) все строматопороидеи в целом, 8) гелиолитоидеи, 9) ругозы, 10) проблематичные водорослевые структуры. Полученные данные приводятся в таблице.

А. Аалоэ и Х. Нестор (1976) подразделяют биогермы юуруского горизонта на четыре типа: 1) зачаточные биогермы, состоящие главным образом из аулоцистид и хализитид, в ридалаской пачке; 2) небольшие неправильно-линзовидные биогермы, состоящие из фавозитид, строматопороидей и инкрустирующих водорослевых образований, в хиллистеской пачке на о-ве Хийумаа; 3) небольшие штокообразные мшанково-кораллово-водорослевые биогермы в основании хиллистеской пачки на п-ве Ридала; 4) крупные линзовидные и сложные биогермы, образованные фавозитидами, хализитидами, мшанками, строматопороидеями, колониальными ругозами и инкрустирующими известковыми водорослями, в верхней части хиллистеской пачки на п-ве Ридала.

* В данной статье полевые рисунки представлены не целиком. 


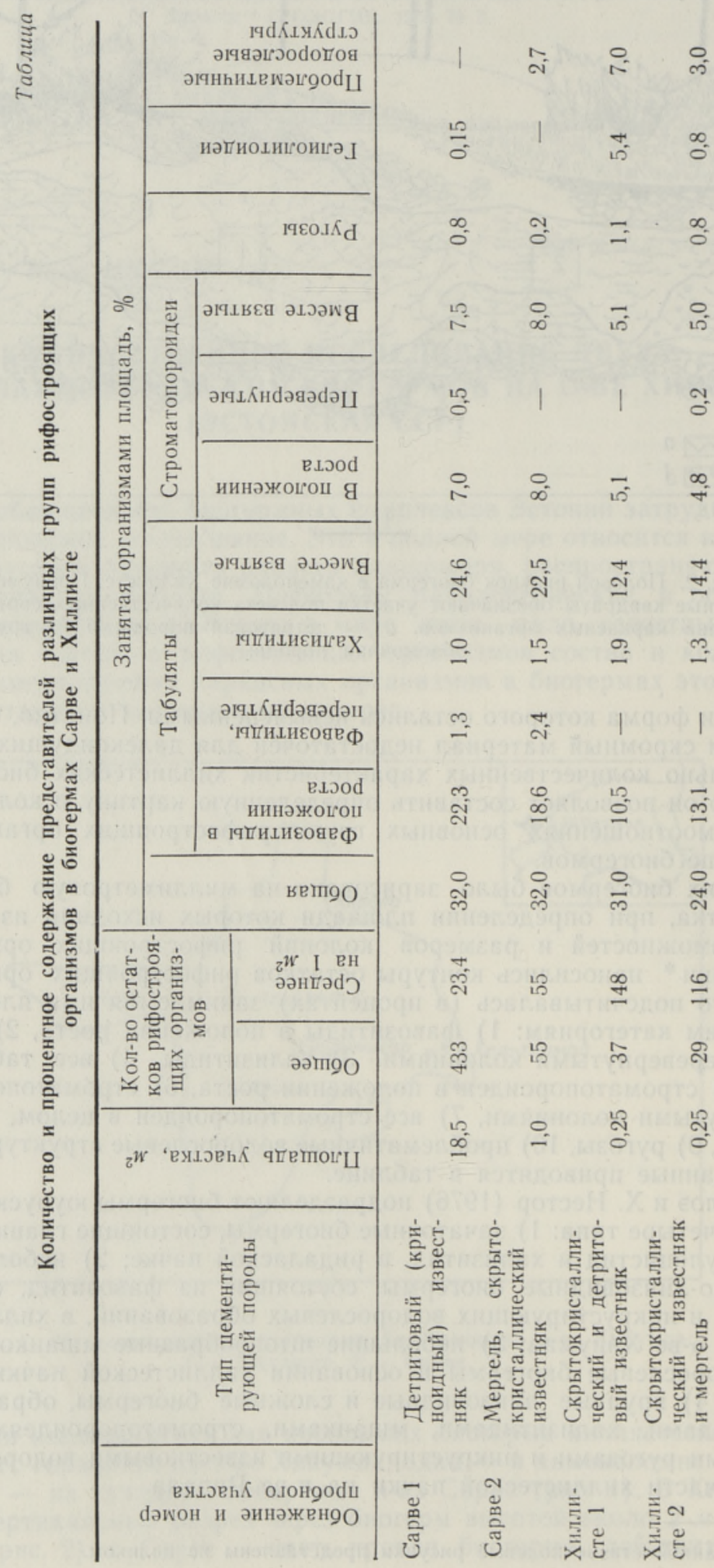



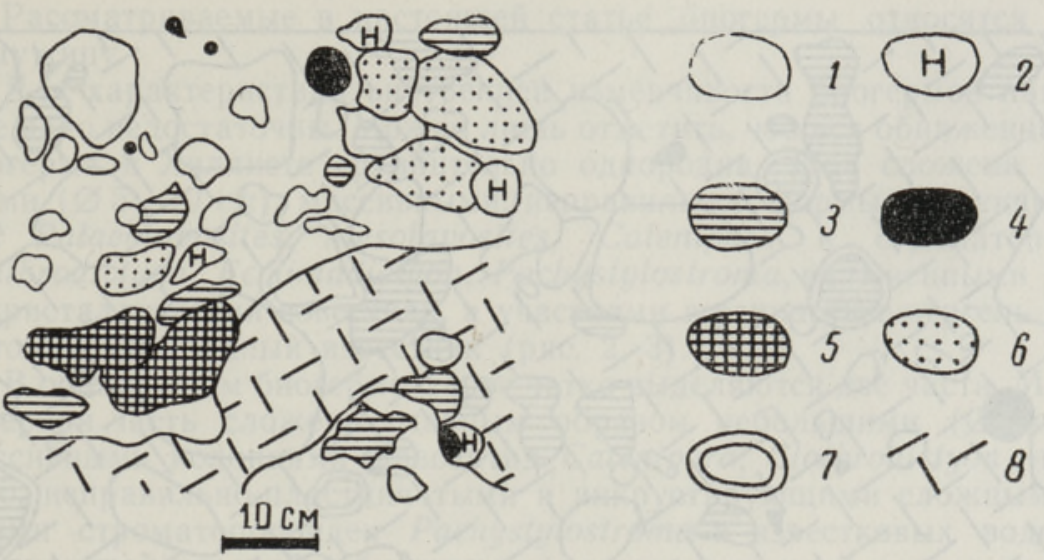

Рис. 3. Расположение рифостроящих организмов в биогерме Хиллисте (см. участок 1 на рис. 2). 1 - фавозитиды, 2 - хализитиды, 3 - строматопороидеи, 4 - ругозы, 5 - гелиолитоидеи, 6 - проблематичные водорослевые структуры, 7 - перевернутые колонии, 8 - детритовая порода.
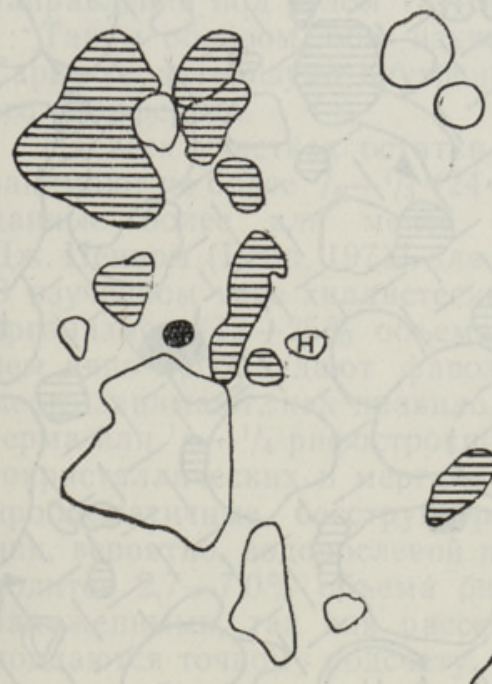

(A)
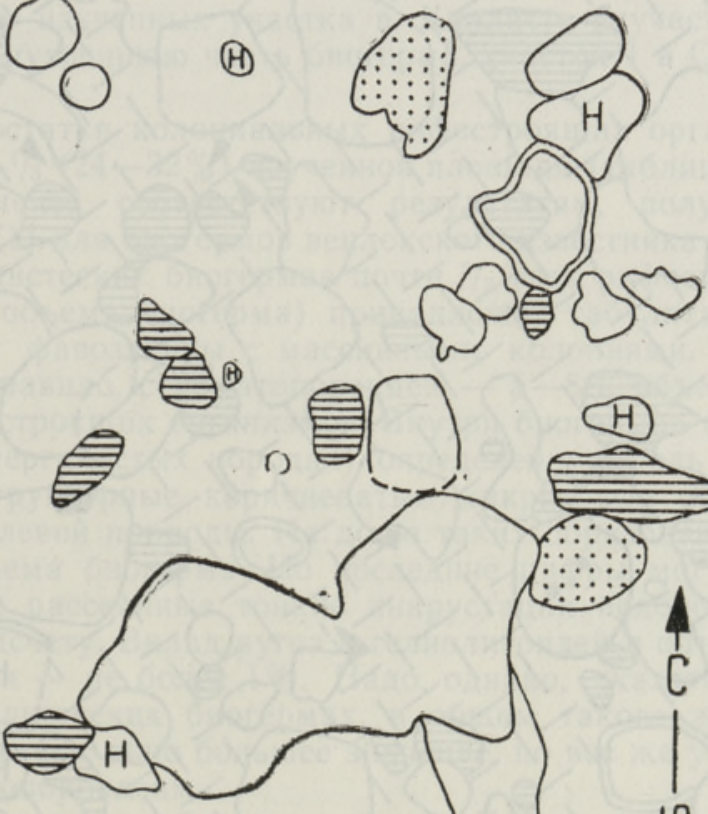

$\theta$
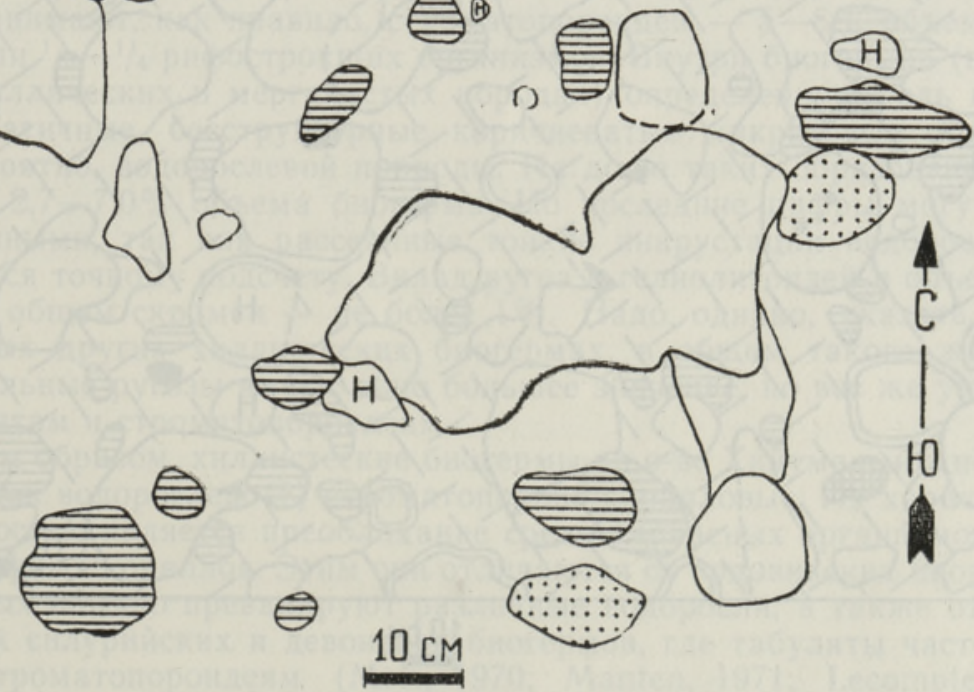

Рис. 4. Расположение рифостроящих организмов в биогерме Сарве (участок 2). Условные обозначения см. на рис. 3 . 


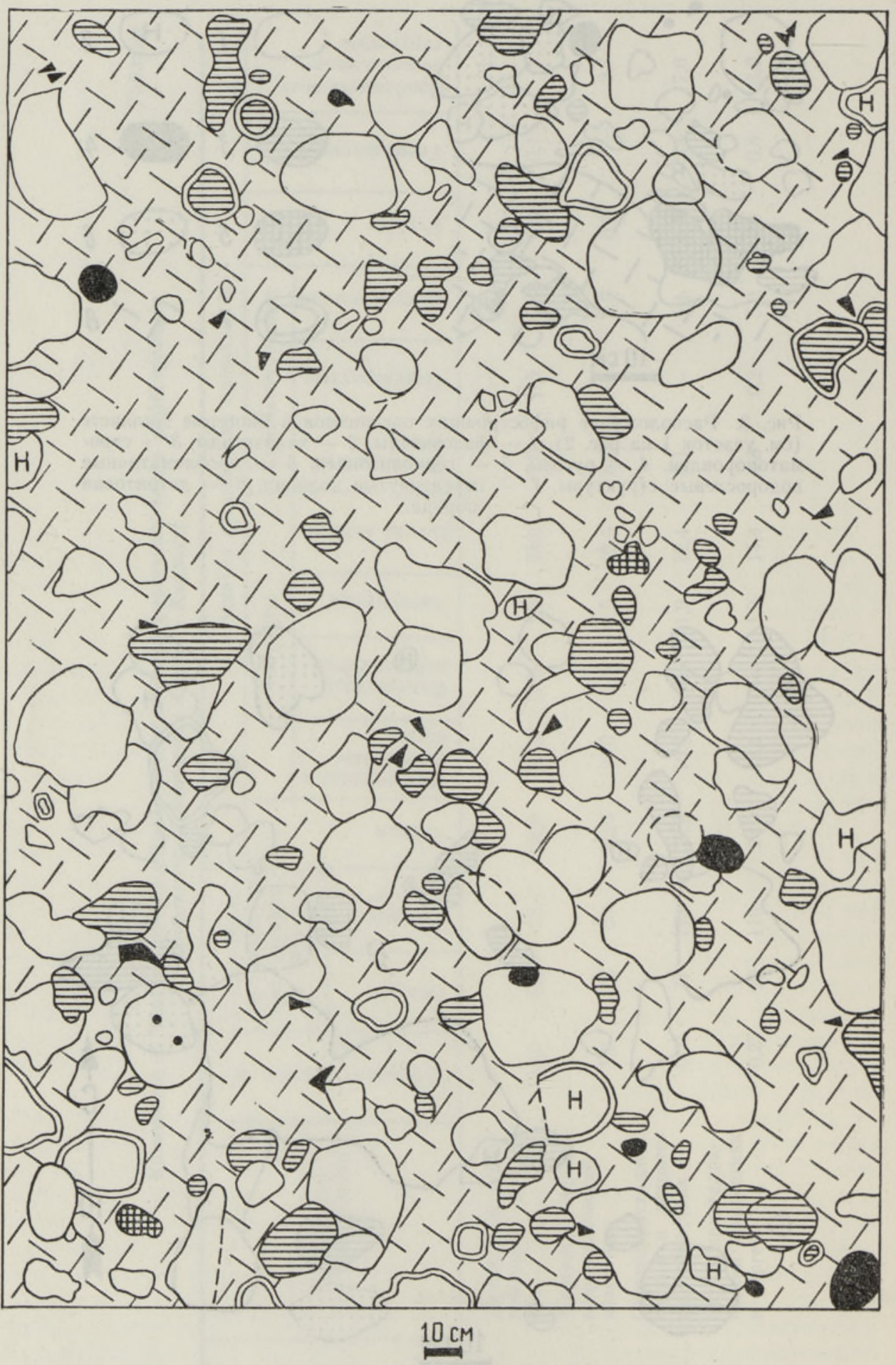

Рис. 5. Расположение рифостроящих организмов в биогерме Сарве (часть участка 1). Условные обозначения см. на рис. 3. 
Расоматриваемые в настоящей статье биогермы относятся ко второму типу.

Для характеристики внутренней изменчивости биогермов наши данные явно недостаточны. Можно лишь отметить, что вся обнаженная часть биогерма в Хиллисте сравнительно однородна. Она сложена небольшими ( $\varnothing 5-10 c м)$, массивными, неправильной формы колониями табулят Palaeofavosites, Mesofavosites, Catenipora и строматопороидей Clathrodictyon, Ecclimadictyon, Pachystylostroma, включенными в скрытокристаллический известняк, а участками в глинистый мергель и в детритовый криноидный известняк (рис. 2,3 ).

В обнаженном биогерме Сарве четко выделяются две части. Меньшая, северная часть сложена главным образом небольшими ( $\varnothing$ до $10 \mathrm{~cm}$ ) массивными колониями фавозитид Catenipora, Clathrodictyon и, кроме того, неправильно-пластинчатыми и инкрустирующими сложными колониями строматопороидеи Pachystylostroma и известковых водорослей. Вмещающей породой в биогерме является глинистый мергель и скрытокристаллический известняк (участок 2, рис. 4). Бо́льшая, южная часть имеет вид «кораллового луга», сложенного крупными ( $\varnothing 15-40$ см) караваеобразными колониями фавозитид и клатродикциид, вмещенными в криноидный известняк (см. таблицу, Сарве 1; рис. 5). Илистая часть биогерма составляет его ядро, в то время как «коралловый луг» образует, очевидно, пологий склон кровли биогерма, покрытой слоистыми обломочно-детритовыми известняками, погружающимися в западном направлении под углом $15-20^{\circ}$.

Таким образом, оба изученных участка в Хиллисте и участок 2 в Сарве характеризуют внутреннюю часть биогерма, участок 1 в Сарве его периферию.

На всех участках остатки колониальных рифостроящих организмов занимают не более $1 / 4-1 / 3(24-32 \%)$ изученной площади (таблица). Эти данные более или менее соответствуют результатам, полученным Дж. Пенном (Penn, 1971) для биогермов венлокского известняка Англии. В изученном типе хиллистеских биогермов почти $2 / 3$ всех рифостроящих организмов (12-25\% объема биогерма) принадлежит табулятам, причем явно преобладают фавозитиды с массивными колониями. Второе место занимают, как правило, строматопороидеи - 5-8\% объема биогерма или $1 / 6-1 / 4$ рифостроящих организмов. Внутри биогермов (в скрытокристаллических и мергелистых породах) определенную роль играют проблематичные, бесструктурные коричневатые микритовые образования, вероятно, водорослевой природы. На долю таких образований приходится $2,7-7,0 \%$ объема биогерма. Но последние цифры могут быть заниженными, так как рассеянные тонкие инкрустации водорослей не поддаются точному подсчету. Вклад ругоз и гелиолитоидей в объем биогерма в общем скромен - не более $1 \%$. Надо, однако, сказать, что в некоторых других хиллистеских биогермах, в общем такого же типа, колониальные ругозы имеют явно бо́льшее значение, но все же уступают и табулятам и строматопороидеям.

Таким образом, хиллистеские биогермы на о-ве Хийумаа можно определить как водорослево(?)-строматопорово-коралловые. Их характерной особенностью является преобладание среди каркасных организмов табулятоморфных кораллов. Этим они отличаются от ордовикских биогермов, в которых обычно превалируют различные водоросли, а также от более молодых силурийских и девонских биогермов, где табуляты часто уступают строматопороидеям (Mori, 1970; Manten, 1971; Lecompte, 1970; и др.). 


\title{
Л И Т Е Р А Т У Р А
}

А алоэ А. О., Н естор Х. Э. 1977. Биогермная фация в юуруском горизонте (нижний лландовери) в Северо-Западной Эстонии. В сб.: Кальо Д. Л. (ред.) Фации и фауна силура Прибалтики. Таллин.

Le compte M. 1970. Die Riffe im Devon der Ardennen und ihre Bildungsbedingungen. Geol. et Palaeontol., 4.

Manten A. A. 1971. Silurian reefs of Gotland. Developments in Sedimentology, 13. Amsterdam, London, New York.

Mori K. 1970. Stromatoporoids from the Silurian of Gotland. Part 2. Stockholm Contrib. Geol., 22.

Penn J. S. W. 1971. Bioherms in the Wenlock Limestone of the Malvern area (Herefordshire, England). Mém. Bureau Rech. Géol. et Minières, 73.

\author{
Институт геологии \\ Академии наук Эстонской ССР
}

Поступила в редакцию 19/III 1976

H. NESTOR, Viiu NESTOR

\section{KAHE HIIUMAA VARALANDOUVERI BIOHERMI KVANTITATIIVNE UURIMINE}

Uuriti riffi moodustavate organismide kvantitatiivseid suhteid kahes juuru lademe hilliste kihistiku biohermis Hiiumaal. Tulemused on toodud tabelis. Organismide skelettidest koosnev karkass moodustab vaid $1 / 4-1 / 3$ biohermse kivimi kogumahust. Põhilised käsitletud biohermi moodustajad olid tabulaadid ( $12-25 \%$ biohermse kivimi kogumahust), stromatopoorid $(5-8 \%)$ ja problemaatilised vetikastruktuurid $(2-7 \%)$.

H. NESTOR, Viiu NESTOR

\section{A QUANTITATIVE STUDY OF TWO EARLY LLANDOVERIAN BIOHERMS ON THE ISLE HIIUMAA (ESTONIAN SSR)}

Quantitative interrelations of reef-building organisms were studied in two small bioherms of the Hilliste Member of the Juuru Stage on the Isle of Hiiumaa (NorthWest Estonia). The results are represented in the Table. Only $1 / 4-1 / 3$ of the whole bioherm volume consists of skeletal framework. The main contributors to bioherm formation were tabulate corals ( $12-25 \%$ of the whole volume of bioherm rock), stromatoporoids $(5-8 \%)$ and problematic algal (?) structures $(2-7 \%)$. 